\title{
Continuous Monoglyceride Production from Palm Fatty Acid Distillate and Glycerol Using Vacuum Reactive Distillation Column
}

\author{
Hanifrahmawan Sudibyo ${ }^{\#}$, Laras Prasakti ${ }^{\#}$, Arief Budiman", Muhammad Fahrurrozi ${ }^{*}$, Rochmadi ${ }^{\#}$ \\ ${ }^{\#}$ Chemical Engineering Department, Gadjah Mada University, Jalan Grafika No. 2 Yogyakarta 55281, Indonesia \\ Email:hanifrahmawan.s@mail.ugm.ac.id, laras.prasakti@mail.ugm.ac.id,mfahrurrozi@ugm.ac.id,rochmadi@ugm.ac.id \\ ${ }^{*}$ Center for Energy Studies, Universitas Gadjah Mada, Jalan Bhinneka Tunggal Ika, Sekip UGM K-1A Yogyakarta 55281, Indonesia \\ Email: abudiman@ugm.ac.id
}

\begin{abstract}
This paper focused on the simulation-based study using Aspen Plus Ver. 7.2 to evaluate possible flow diagram processes and process configurations related to the continuous production of monoglyceride from palm fatty acid distillate-glycerol esterification using strong acidic cation resin in a reactive distillation column. Basic operating conditions evaluated was the operating pressure. Evaluation between atmospheric and vacuum operating pressure showed that the latter could give better product quality by avoiding the product from cracking or destructed due to too high operating temperature when the operating pressure was atmospheric ( 1 bar). The preferred vacuum pressure was 0.05 bar which resulted in the maximum temperature at the bottom stream of distillation column was about $335^{\circ} \mathrm{C}$, lower than a maximum allowable temperature which was $350^{\circ} \mathrm{C}$. On the other hand, atmospheric condition resulted in maximum temperature at the stream was about $520^{\circ} \mathrm{C}$. Afterward, two scenarios were evaluated which were using one reactive distillation column with high reboiler duty combined with only one distillation column (Scenario-1) or using one reactive distillation column with moderate reboiler duty combined with two distillation columns (Scenario-2) to have high purity monoglycerides. Scenario-2 showed a little bit more sophisticated flowsheetings but yielded in less overall energy consumption for relatively the same monoglycerides purity at the bottom stream of the distillation column.
\end{abstract}

Keywords - Reactive distillation; palm fatty acid distillate; monoglyceride; vacuum distillation; ASPEN Simulation

\section{INTRODUCTION}

Recently, monoglycerides presented as one of the most wanted products derived from free fatty acids [1], [2], [3]. On the other hand, the current interesting fatty acid source was palm fatty acid distillate (PFAD). The PFAD was the byproduct of crude palm oil (CPO) physical refining with the amount of 3.66 ton/100 ton CPO produced [4], [5] composed of linoleic acid and oleic acid as the major components [6], [7].

Most of the studies related to monoglyceride production through PFAD esterification with glycerol were experimental-based and laboratory scale. Meanwhile, to fulfill the market demand and to have aggressive supply, monoglyceride production must be conducted continuously and in industrial scale. Therefore, this work tried to identify the most optimum process configuration and condition to have the process economically feasible. Since water presented as the byproduct of esterification process, one thing to be considered was how to remove the water easily from the reaction mixture in the continuous process.
Fortunately, previous work by Poddar et al. [8], Wu et al. [9], and Singha et al. [10] showed that fatty acid esterification could be combined with the separation process using reactive distillation column.

The approach used in this study was simulation-based. The simulation-based approach provides such advantages that cost and time to conduct real continuous experiment could be managed efficiently by identifying the "do's and don'ts" related to the process condition and configuration during the experiment [11]. The simulation conducted in this work focused on the selection of the best flow diagram process and its configuration by focusing on both product purity and energy consumption by each option.

\section{MATERIALS AND METHODS}

Since this reaction was considered as a heterogeneous reaction, there were two capable reaction mechanisms to describe the phenomenon, which were Langmuir Hinshelwood, and Eley - Rideal. The previous study by Sudibyo et al. [6] suggested that heterogeneous esterification of PFAD and glycerol were best carried out using Langmuir- 
Hinshelwood mechanism. The esterification reaction pathways for the PFAD components were described in Eq. 1 - Eq. 6. As stated in Eq. 1 - Eq. 6, the reactions were irreversible towards the product. This assumption was acceptable because the water was removed using xylenebased reflux system [3].

$$
\begin{gathered}
\text { Linoleic acid }+ \text { Glycerol } \rightarrow \text { Monolinolein }+\mathrm{H}_{2} \mathrm{O} \\
\text { Linoleic acid }+ \text { Monolinolein } \rightarrow \text { Dilinolein }+\mathrm{H}_{2} \mathrm{O} \\
\text { Linoleic acid }+ \text { Dilinolein } \rightarrow \text { Trilinolein }+\mathrm{H}_{2} \mathrm{O} \\
\text { Oleic acid }+ \text { Glycerol } \rightarrow \text { Monoolein }+\mathrm{H}_{2} \mathrm{O} \\
\text { Oleic acid }+ \text { Monoolein } \rightarrow \text { Diolein }+\mathrm{H}_{2} \mathrm{O} \\
\text { Oleic acid }+ \text { Diolein } \rightarrow \text { Triolein }+\mathrm{H}_{2} \mathrm{O}
\end{gathered}
$$

The data obtained from the batch experiment was then transferred into continuous process simulation. The simulations were conducted using chemical process design software simulator, Aspen Plus Ver. 7.2.

The simulation aimed to predict continuous process performance of PFAD-glycerol esterification in various operating conditions as well as determining the feasible alternatives to obtain high purity product. In the ASPEN simulation, the rate of reaction equations (including its kinetics constants value) adopted from Sudibyo et al. [6] still needed to be modified into Power Law form as written in Eq. 7 - Eq. 12.

$$
\begin{gathered}
-r_{2}=\frac{k_{r 2}}{K_{G}^{2}} \cdot C_{L} \cdot C_{M L} \cdot C_{G}^{-2}=k_{2}^{\prime} \cdot C_{L} \cdot C_{M L} \cdot C_{G}^{-2} \\
-r_{3}=\frac{k_{r 3}}{K_{G}^{2}} \cdot C_{L} \cdot C_{D L} \cdot C_{G}^{-2}=k_{3}^{\prime} \cdot C_{L} \cdot C_{D L} \cdot C_{G}^{-2} \\
-r_{4}=\frac{k_{r 4}}{K_{G}^{2}} \cdot C_{O} \cdot C_{G}^{-1}=k_{4}^{\prime} \cdot C_{O} \cdot C_{G}^{-1} \\
-r_{1}=\frac{k_{r 1}}{K_{G}^{2}} \cdot C_{L} \cdot C_{G}^{-1}=k_{1}^{\prime} \cdot C_{L} \cdot C_{G}^{-1} \\
-r_{5}=\frac{k_{r 5}}{K_{G}^{2}} \cdot C_{O} \cdot C_{M O} \cdot C_{G}^{-2}=k_{5}^{\prime} \cdot C_{O} \cdot C_{M O} \cdot C_{G}^{-2} \\
-r_{6}=\frac{k_{r 6}}{K_{G}^{2}} \cdot C_{O} \cdot C_{D O} \cdot C_{G}^{-2}=k_{6}^{\prime} \cdot C_{O} \cdot C_{D O} \cdot C_{G}^{-2}
\end{gathered}
$$

The Power Law form in Eq. 7 - Eq. 12 assumed that there was a molar excess of glycerol used as a reactant. In this study, the molar ratio of PFAD and glycerol used was 1:3. By adapting the reaction kinetics constants value obtained from the previous study by Sudibyo et al. [6], new reaction kinetics constants value related to the Power Law form (Eq. 7 - Eq. 12) were obtained and was shown in Table 1.

In the simulation, reactive distillation was performed within Radfrac model. The Radfrac model was selected due to its capability in performing the rigorous calculation of mass balance, enthalpy balance and phase equilibrium for the vapour-liquid system. Appropriate property method should be chosen carefully in order to obtain reliable results.
The UNIQUAC model was selected as the property method to perform the simulation as it was also suggested by Bhatia et al. [12], Banchero et al. [13], and Lazzus [14]. Beside the Radfrac model and UNIQUAC property method, other process equipment models such as DSTWU column, heater, mixer and heat exchanger were also considered for estimating the most suitable system configuration. Reaction kinetics constants from Table 1 were used to proceed the Radfrac simulation of reactive stages. Vacuum operating pressure was preferred to start the simulation in the purpose of finding the best-operating conditions since the boiling point of the involving components were very high. Several key parameters were first determined to run basic reactive distillation simulation. The parameters were shown in Table 2.

Aspen Plus Ver. 7.2 had provided the relatively vast component database. However, for components which were not contained in the database, new basic data needed to be supplied into the simulation. In this step, the molecular structures of monolinolein, monoolein, dilinolein, diolein, trilinolein, and triolein were supplied to the simulation by drawing the molecular structure. Physical and chemical properties of the aforementioned components were then calculated by the simulator based on chemical bonds and the corresponding atoms.

Before proceeded into the calculation, the diameter of the reactive distillation column must be calculated. The calculation followed Eq. 13 and Eq. 14 [15].

$$
\begin{gathered}
\hat{\mathrm{u}}_{\mathrm{v}}=\left(-0.171 \mathrm{l}_{\mathrm{t}}^{2}+0.27 \mathrm{l}_{\mathrm{t}}-0.047\right) \cdot\left[\frac{\rho_{L}-\rho_{V}}{\rho_{V}}\right]^{0.5} \\
\mathrm{D}_{\mathrm{C}}=\sqrt{\frac{4 \cdot \widehat{\mathrm{V}}_{\mathrm{w}}}{\pi \cdot \rho_{\mathrm{c}} \cdot \widehat{\mathrm{u}}_{\mathrm{v}}}}
\end{gathered}
$$

In this simulation, there were two configurations evaluated. In both scenarios, remaining glycerol was recycled and mixed with fresh glycerol to become warm glycerol feed stream. Relatively high-temperature product stream made it possible to design heat integration within the process. In the simulation, product stream having relatively high temperature was used as heating fluid in the pre-heater (HE-01).

1) Scenario-1: In this scenario, the reactive distillation column was followed by one distillation column to separate glycerol and water. In the reactive distillation column, product and reactant separation was achieved by increasing reboiler duty. The configuration of scenario-1 was shown in Fig. 1.

2) Scenario-2: The scenario-2 used 2 distillation columns after reactive distillation column. The first distillation column (DC-01) was for separating glycerol and water, while the second one (DC-02) was for separating the reaction product and glycerol. Process flow diagram of Scenario-2 was shown in Fig. 2. 
TABLE I

REACTION Kinetics CONSTANTS VALUE FOR POWER-LAW-BASED RATE OF REACTION EQUATIONS

\begin{tabular}{|c|c|c|}
\hline \multirow{2}{*}{ Constants } & \multicolumn{2}{|c|}{ Arrhenius constants } \\
\cline { 2 - 3 } & $\mathbf{A}$ & $\mathbf{E}, \mathbf{c a l} / \mathbf{m o l}$ \\
\hline $\mathrm{k}_{1}{ }^{\prime}[\mathrm{mol} /(\mathrm{L} \cdot \mathrm{min})]$ & $3.10 \mathrm{E}+05$ & $8,114.91$ \\
\hline $\mathrm{k}_{2}{ }^{\prime}[\mathrm{mol} /(\mathrm{L} \cdot \mathrm{min})]$ & $3.12 \mathrm{E}+05$ & $18,651.97$ \\
\hline $\mathrm{k}_{3}{ }^{\prime}[\mathrm{mol} /(\mathrm{L} \cdot \mathrm{min})]$ & $6.24 \mathrm{E}+10$ & 25,012 \\
\hline $\mathrm{k}_{4}{ }^{\prime}[\mathrm{mol} /(\mathrm{L} \cdot \mathrm{min})]$ & $3.07 \mathrm{E}+05$ & $8,045.32$ \\
\hline $\mathrm{k}_{5}{ }^{\prime}[\mathrm{mol} /(\mathrm{L} \cdot \mathrm{min})]$ & $2.61 \mathrm{E}+08$ & 19,998 \\
\hline $\mathrm{k}_{6}{ }^{\prime}[\mathrm{mol} /(\mathrm{L} \cdot \mathrm{min})]$ & $5.80 \mathrm{E}+08$ & 30,100 \\
\hline
\end{tabular}

TABLE II

OPERATING CONDITION FOR BASE SIMULATION

\begin{tabular}{|l|c|}
\hline \multicolumn{1}{|c|}{ Parameter } & Value \\
\hline PFAD flow basis & 10 tons/day \\
\hline Glycerol-PFAD molar ratio & 3 \\
\hline Total number of stages & 9 \\
\hline Total number of reactive stages & 3 (from 4 to 6) \\
\hline Condenser type (stage 1) & Total \\
\hline Reboiler type (stage 9) & Kettle \\
\hline
\end{tabular}

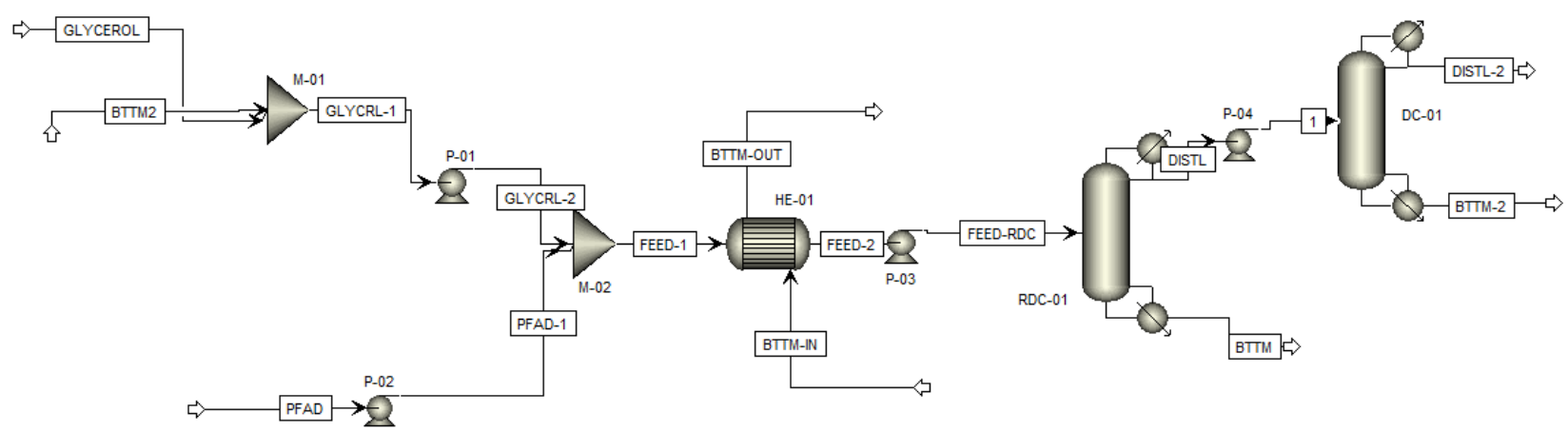

Fig. 1 Scenario-1 process flow diagram

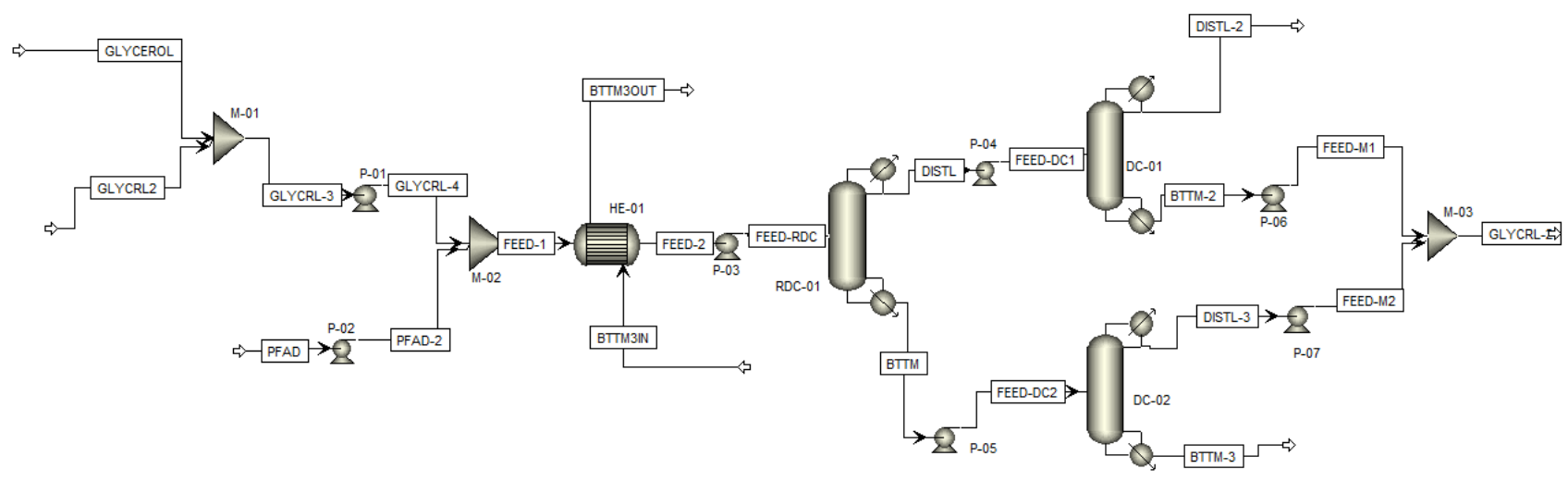

Fig. 2 Scenario-2 process flow diagram

\section{RESULTS AND DISCUSSIONS}

The diameter of the reactive distillation column was calculated using Eq. 19 by setting the plate spacing of $0.6 \mathrm{~m}$, vapor flow rate of $0.07835 \mathrm{~kg} / \mathrm{s}$, liquid phase density of $802.19 \mathrm{~kg} / \mathrm{m}^{3}$, and gas phase density of $0.37 \mathrm{~kg} / \mathrm{m}^{3}$. Afterward, the diameter was calculated using Eq. 14 which resulted in 0.33 meter in diameter.

$$
\begin{gathered}
\hat{\mathrm{u}}_{\mathrm{v}}=\left(-0.171(0.6)^{2}+0.27(0.6)-0.047\right) \cdot\left[\frac{802.19-0.37}{0.37}\right]^{0.5} \\
\mathrm{D}_{\mathrm{C}}=\sqrt{\frac{4(0.07835)}{\pi(802.19)(2.5)}}=0.33 \mathrm{~m}
\end{gathered}
$$


Correlation between several parameters towards the purity of product could be estimated by utilizing Sensitivity Analysis model analysis tools in Aspen Plus. In this simulation, the reactive distillation column had nine sievetray stages which consisted of 3 rectifying stages, 3 reactive stages, and 3 enriching stages. The Fig. 3 showed sensitivity results of product purity as the function of molar reflux ratio, preheater temperature, reboiler duty and feed stage position. Based on Fig. 3 (a), higher reflux ratio resulted in lower product purity in the bottom stream which is represented by monolinolein and monoolein mass fraction. Although glycerol was mostly split into top stream, the increasing reflux ratio obviously caused more glycerol in bottom

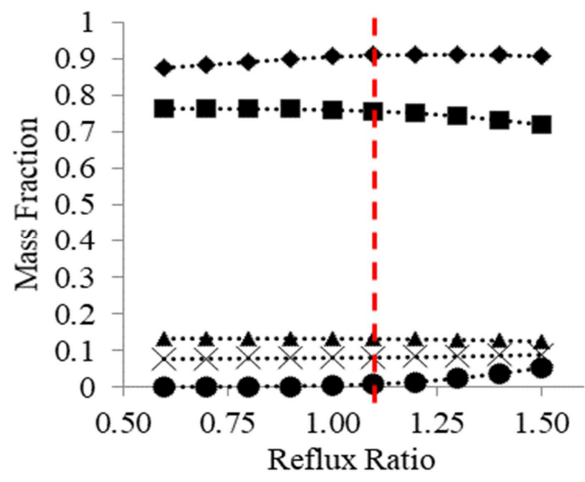

(a)

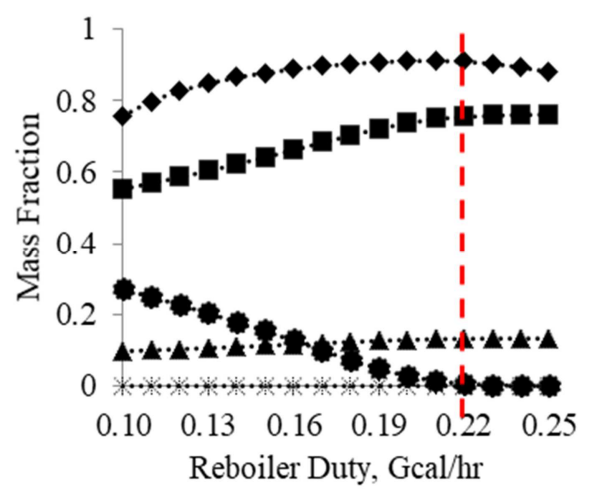

(c) product thus reducing product purity. In Fig. 3 (b), greater feed temperature enabled the better product purification. In Fig. 3 (c), the increasing reboiler duty became relatively insignificant within the value greater than $0.21 \mathrm{Gcal} / \mathrm{hr}$.

Sensitivity results in Fig. 3 (d) showed that selection of the feed stage relatively close to reboiler would reduce the mass fraction of reaction product (mono-, di-, and triglycerides) both in the top stream and in the bottom stream. The reason was, by feeding the feed close to the reboiler, the reactants (PFAD and glycerol) would directly vaporize while the optimum rate of reaction occurred in the liquid phase. All optimum conditions related to those four parameters were marked by a red dashed line in each graph.

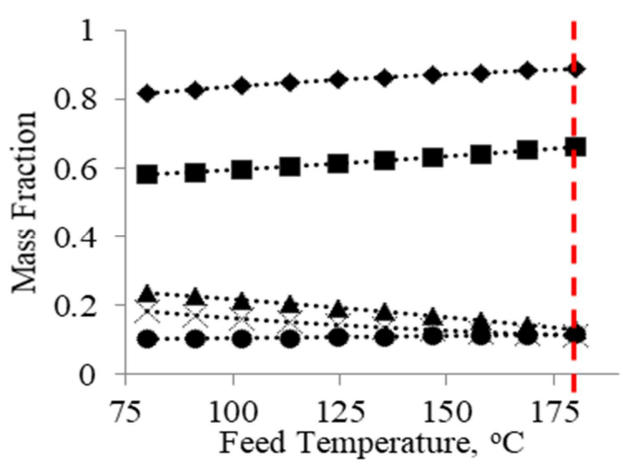

(b)

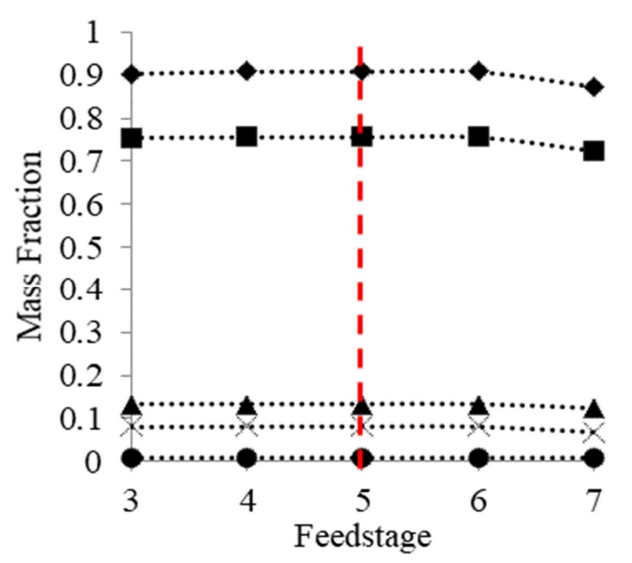

(d)

Fig. 3 Profile of column compositions (a). as a function of reflux ratio (b). as a function of heater temperature (c). as a function of reboiler duty (d). as a function of feed stage position with $\bullet$ :Glycerol-Top $\mathbf{~ : ~ M o n o l i n o l e i n ~} \boldsymbol{\Delta}$ : Monoolein X: Water-Top •: Glycerol-Bottom

TABLE III

CALCULATION RESUlTS FOR SCENARIO-1 AND SCENARIO-2 UNDER VACUUM PRESSURE CONDITION

\begin{tabular}{|l|r|l|r|l|}
\hline \multicolumn{1}{|c|}{ Parameters } & \multicolumn{2}{|c|}{ Scenario-1 } & \multicolumn{2}{c|}{ Scenario-2 } \\
\hline Monolinolein purity & $75.2 \%$ & FFA & $75.4 \%$ & FFA \\
\hline Monoolein purity & $13.2 \%$ & Conversion: & $13.2 \%$ & Conversion: \\
\hline Dilinolein purity & $10.4 \%$ & $99.7 \%$ & $10.4 \%$ & $99.8 \%$ \\
\hline Energy consumption & $0.327 \mathrm{Gcal} / \mathrm{hr}$ & & $0.293 \mathrm{Gcal} / \mathrm{hr}$ & \\
\hline
\end{tabular}




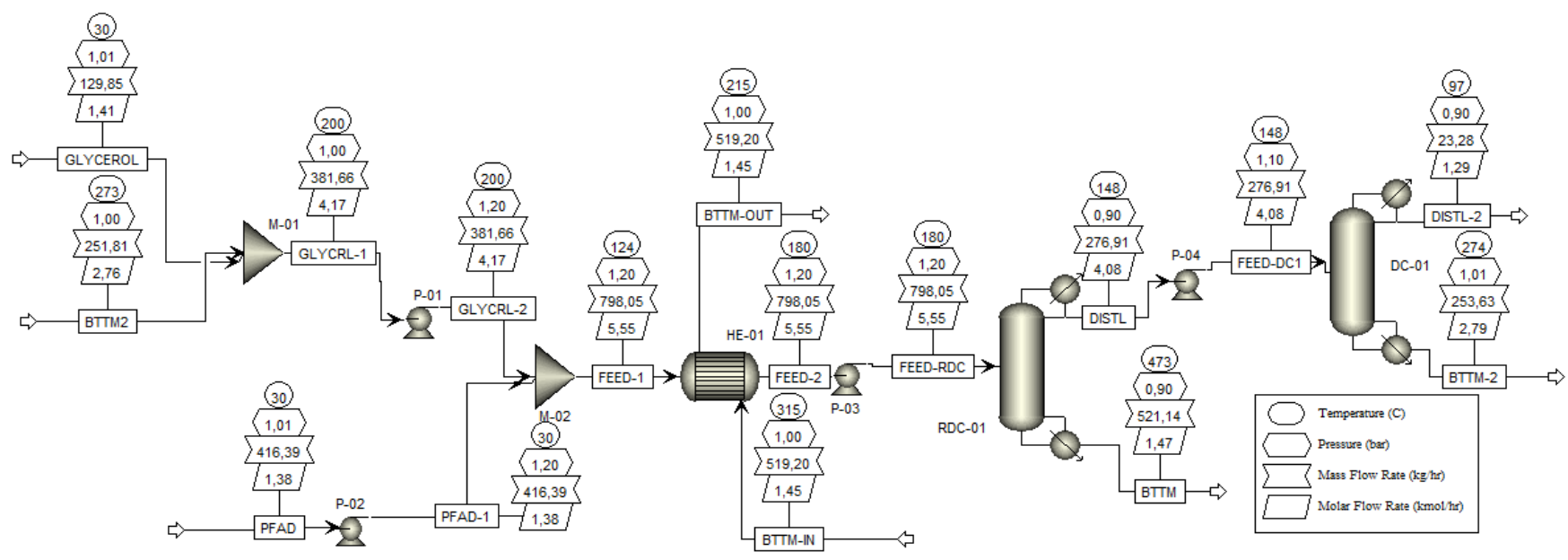

Fig. 4 Calculation result for scenario-1 process flow diagram under atmospheric pressure condition (1 bar)

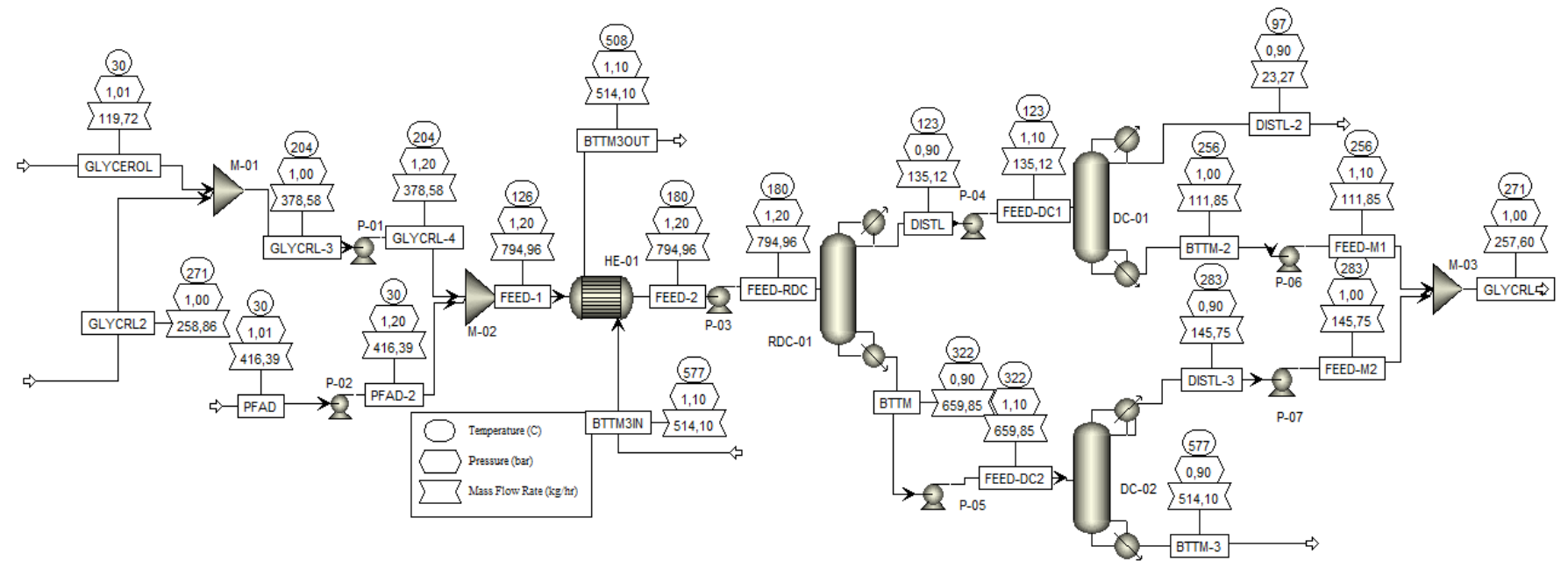

Fig. 5 Calculation result for scenario-2 process flow diagram under atmospheric pressure condition (1 bar)

The Fig. 4 and Fig. 5 stood for atmospheric pressure system in the reactive distillation system. Unfortunately, operating the continuous monoglycerides production under atmospheric pressure condition might lead to the destruction or the cracking of carbon bonding in the reactant and product due to extremely high temperature. From Fig. 4 (the bottom stream of RDC-01) and Fig. 5 (the bottom stream of DC-02), the temperature of the stream was greater than $500^{\circ} \mathrm{C}$, much higher than the allowable operating temperature to keep the quality of the product which was $350^{\circ} \mathrm{C}$ [16].

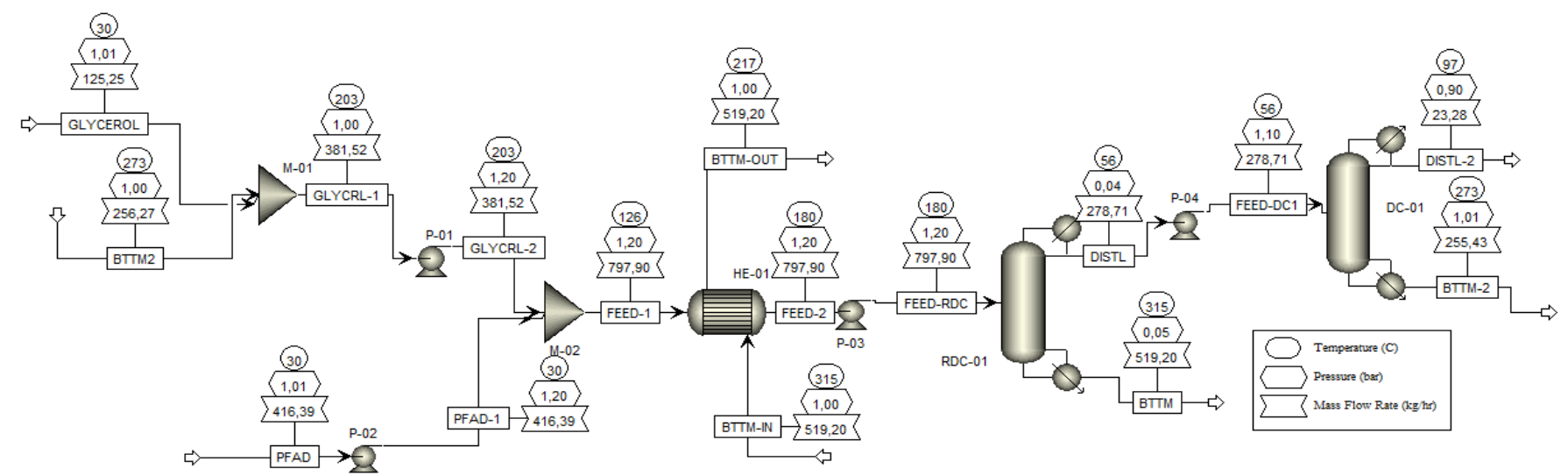

Fig. 6 Calculation result for scenario-1 process flow diagram under vacuum pressure 


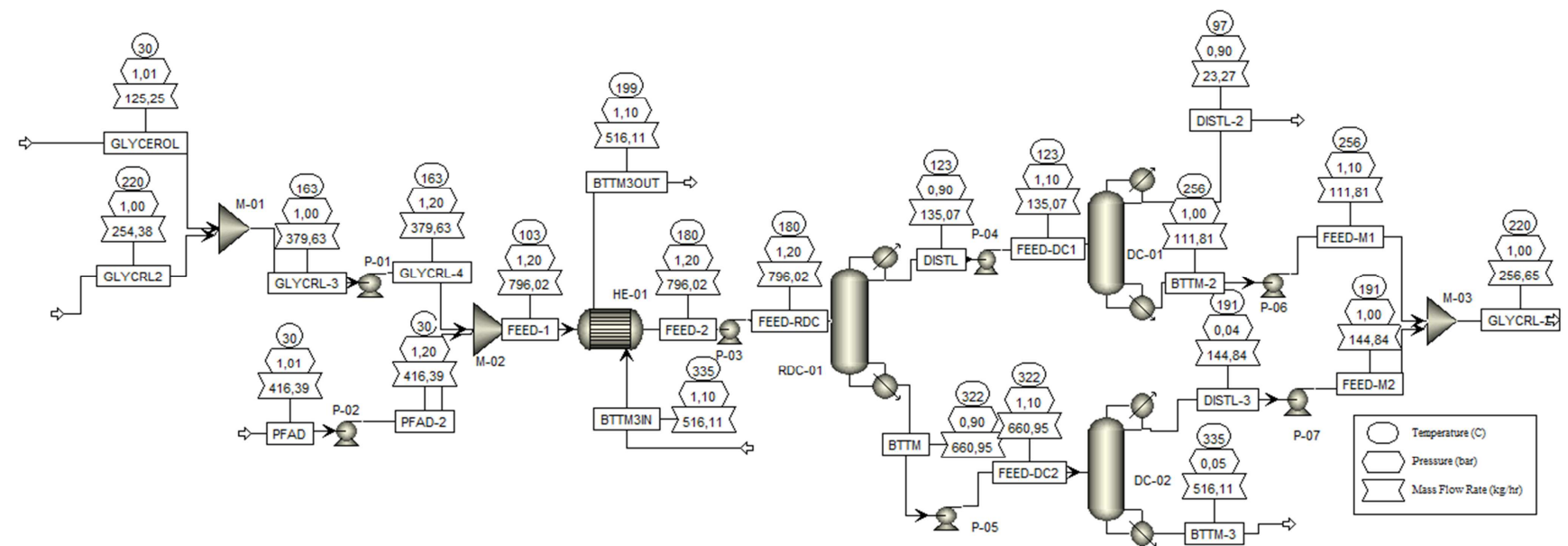

Fig. 7 Calculation result for scenario-2 process flow diagram under vacuum pressure

Simulation results revealed that running the process with a vacuum pressure of 0.05 bar could lower the reaction product temperature to $320^{\circ} \mathrm{C}$ (Fig. 6 and Fig. 7). Therefore, atmospheric pressure condition is avoided. Summary of the simulation for both scenarios under vacuum condition was shown in Table 3. Preheating process before entering reactive distillation column is carried out using shell and tube heat exchanger with the heat duty of $0,16 \mathrm{Gcal} / \mathrm{hr}$ was negligible. This was based on the utilization of the hot reaction product stream as the heating medium. Simulation result also showed that for both scenarios, the most consuming energy equipment was reactive distillation column because of the reboiler's heat duty. Although the Scenario-2 needed more columns than Scenario-1, the Scenario-2 consumed lower energy to yield relatively the same product purity.

\section{IV.CONCLUSIONS}

Continuous production of monoglycerides in reactive distillation column preferred vacuum pressure to avoid the cracking or the destruction of carbon chain in the monoglycerides. Besides, to have a high purity of monoglycerides, the separation cannot be forced only in the reactive distillation column. Further separation must be conducted separately to purify the monoglycerides (Scenario-2) to have lower energy consumption.

\section{NOMENCLATURE}

$\begin{array}{lll}\mathrm{kr}_{1,4} & \begin{array}{l}\text { reaction rate constant of } \\ \text { monoglycerides formation } \\ \mathrm{kr}_{2,5}\end{array} & \begin{array}{l}\text { reaction rate constant of } \\ \text { diglycerides formation } \\ \text { reaction rate constant of } \\ \text { triglycerides formation }\end{array} \\ \mathrm{kr}_{3,6} & \mathrm{~L} \cdot \mathrm{mol}^{-1} \cdot \mathrm{min}^{-1} \\ \mathrm{~K}_{\mathrm{G}} & \begin{array}{l}\text { adsorption equilibrium constant } \\ \text { of glycerol }\end{array} & \mathrm{L} \cdot \mathrm{mol}^{-1} \cdot \mathrm{min}^{-1} \\ \mathrm{C}_{\mathrm{i}} & \begin{array}{l}\text { concentration of component } \mathrm{i} \\ \text { maximum allowable vapor }\end{array} & \mathrm{mol} \cdot \mathrm{L}^{-1} \\ \hat{\mathrm{u}}_{\mathrm{v}} & \begin{array}{l}\text { m.s } \\ \text { velocity based on the gross }\end{array} & \\ & \begin{array}{l}\text { column cross-sectional area } \\ \text { plate spacing }(0.5-1.5 \mathrm{~m})\end{array} & \mathrm{m} \\ \mathrm{l}_{\mathrm{t}} & \begin{array}{l}\text { maximum vapor rate } \\ \widehat{\mathrm{V}}_{\mathrm{w}}\end{array} & \mathrm{kg} \cdot \mathrm{s}^{-1}\end{array}$

Abbreviations

PFAD Palm Fatty Acid Distillate

CPO Crude Palm Oil

Subscripts

G glycerol

L linoleic acid

O oleic acid

ML monolinolein

DL dilinolein

TL trilinolein

MO monoolein

DO diolein

TO triolein

\section{ACKNOWLEDGMENT}

The authors are grateful for the official license of ASPEN ver. 7.2 given by Chemical Engineering Department, Universitas Gadjah Mada to conduct this simulation-based study. Special gratitude is also for General Directorate of High Education of Indonesia due to the financial support through Competency Research Grant 2014/2015.

\section{REFERENCES}

[1] P. Chetpattananondh, and C. Tongurai, "Synthesis of high purity monoglycerides from crude glycerol and palm stearin", Songklanakrin J. Sci. Technol. vol. 30(4), pp. 515-521, 2008.

[2] L.Y. Lee, N.L. Chin, C.H. Lim, Y.A. Yusof, R. A.Talib, "Saturated Distilled Monoglycerides Variants in Gel-form Cake Emulsifiers", Agric. Agric. Sci. Procedia vol. 2, pp. 191-198, 2014.

[3] A. Alfutimie, N. Al-Janabi, R. Curtis, G.J.T.Tiddy, "The Effect of monoglycerides on the crystallisation of triglyceride", Colloids Surf., $A$ vol. 494, pp. 170-179, 2016

[4] B.S. Chu, S.Y. Quek, and B.S. Baharin, "Optimization of enzymatic hydrolysis for concentration of vitamin $\mathrm{E}$ in palm fatty acid distillate", Food Chem. vol. 80, pp. 295 - 302, 2003.

[5] L.A.S.do Nascimento, R.S. Angélica, C.E.F. da Costa, J.R. Zamian, G.N. da Rocha Filho, "Conversion of waste produced by the deodorization of palm oil as feedstock for the production of biodiesel using a catalyst prepared from waste material", Bioresour. Technol., vol. 102(17), pp. 8314-8317, 2011.

[6] H. Sudibyo, Rochmadi, and M. Fahrurrozi, "Kinetics Study of Palm Fatty Acid Distillate Esterification with Glycerol over Strong Acidic Cation Exchanger Tulsion 42SM", Engineering Journal vol. 21(1), pp. $45-61,2017$.

[7] I.M. Lokman, U. Rashid, and Y.H. Taufiq-Yap, "Meso- and macroporous sulfonated starch solid acid catalyst for esterification of 
palm fatty acid distillate", Arabian J. Chem. vol. 9(2), pp. 179-189, 2016.

[8] T. Poddar, A. Jagannath, and A. Almansoori, "Use of reactive distillation in biodiesel production: A simulation-based comparison of energy requirements and profitability indicators", Appl. Energ. vol. 185, pp. 985-997, 2017.

[9] Y.C. Wu, H.Y. Lee, C.Y. Tsai, H.P. Huang, and I.L. Chien , "Design and control of a reactive-distillation process for esterification of an alcohol mixture containing ethanol and n-butanol", Comput. Chem. Eng. vol. 57, pp. 63-77, 2013.

[10] D. Singha, R.K. Gupta, V. Kumar, "Simulation of a plant scale reactive distillation column for esterification of acetic acid", Comput. Chem. Eng. Vol.73, pp. 70-81, 2015.

[11] K. Prasertsit, C. Mueanmas, and C. Tongurai, "Transesterification of palm oil with methanol in a reactive distillation column", Chem. Eng. Process. Process Intensif. vol. 70, pp. 204-15, 2013.

[12] S. Bhatia, A.R. Mohamed, A.L. Ahmad, and S.Y. Chin, "Production of isopropyl palmitate in a catalytic distillation column: Comparison between experimental and simulation studies", Comput. Chem. Eng. vol. 31, p. 1187, 2007.

[13] M. Banchero, R.D. Kusumaningtyas, and G. Gozzelino, "Reactive distillation in the intensification of oleic acid esterification with methanol - A simulation case-study", J. Ind. Eng. Chem. vol. 20, pp 4242-4249, 2014.

[14] J.A. Lazzús, "Optimization of activity coefficient models to describe vapor-liquid equilibrium of (alcohol + water) mixtures using a particle swarm algorithm", Comput. Math. Appl. vol. 60(8), pp. 22602269, 2010 .

[15] R.K. Sinnott, Coulson \& Richardson's Chemical Engineering Vol. 6 4th edition Chemical Engineering Design. Massachusetts, USA: Elsevier Butterworth-Heinemann, 2005.

[16] S.Quoilin. M.V.D. Broek, S. Declaye, P. Dewallef, V. Lemort, "Techno-economic survey of Organic Rankine Cycle (ORC) systems", Renew. Sust. Energ. Rev. vol. 22, pp. 168-186, 2013. 